\title{
ASSESSMENT THE EFFECT OF SKIDDING TECHNIQUES ON THE ECOLOGICAL EFFICIENCY OF THE SKIDDING TRACTOR
}

\author{
Igor GRIGOREV ${ }^{1 *}$, Ol'ga KUNICKAYA ${ }^{1}$, Albert BURGONUTDINOV ${ }^{2}$, Olga BURMISTROVA $^{3}$, \\ Varvara DRUZYANOVA ${ }^{4}$, Nikolay DOLMATOV ${ }^{5}$, Anna VORONOVA ${ }^{6}$, Alexey KOTOV ${ }^{7}$ \\ ${ }^{1}$ University Yakut State Agricultural Academy, Yakutsk, Russian Federation \\ ${ }^{2}$ Perm National Research Polytechnic University, Perm, Russian Federation \\ ${ }^{3}$ Ukhta State Technical University, Ukhta, Russian Federation \\ ${ }^{4}$ Northeastern Federal University named after M. K. Ammosov, Yakutsk, Russian Federation \\ ${ }^{5}$ Don State Agrarian University, Novocherkassk, Russian Federation \\ ${ }^{6}$ Federal State Budget Educational Institution of Higher Education "Petrozavodsk State University", \\ Petrozavodsk, Russian Federation \\ ${ }^{7}$ University Moscow State Technical University N. E. Bauman (Mytishchi branch), Mytishchi, Russian \\ Federation \\ *Corresponding author: iv.grigorev@ rambler.ru
}

\begin{abstract}
The study aims to build a model for the assessment of soil compaction processes, which take place under the influence of individual components of the skidding system such as a forwarder and a log being moved over the terrain. This aim is relevant in the context of forest preservation and ecological footprint-related issues. The model of a single log impact on the soil is based on establishing calculation formulas for determining soil compaction factors and shelterbelt size. The efficiency of the model was assessed on different soil categories and compared to experimental findings. The value of relative soil compaction within the trail boundary and the size rs of the maximum compaction area in the radial direction from the track, the width of the shelterbelt of undergrowth or cut-to-length root system were estimated based on the initial contact parameters.
\end{abstract}

Keywords: high latitude forests, permafrost soils, reduction of environmental consequences

\section{INTRODUCTION}

Forests ensure the environmental security of areas and the planet as a whole. Therefore, biodiversity acquires undisputable importance for the full enjoyment of human rights, in particular the right to live in a healthy environment [1]. Modern forest management, conservation, and regeneration methods must meet the increased social, environmental, and economic needs.

Increasing attention is paid to improving the efficiency of timber harvesting and reforestation processes, which is evaluated by multiple factors such as physical and mechanical properties of the soil, parameters of the vehicle body, tires, loading capacity of wheeled vehicles, etc. [2]. Among others, a significant role plays the eco-efficiency index, i.e., correlation between economic value added and environmental harm [3]. One of the most important indicators for the assessment of the environmental efficiency of harvesting processes is the integral indicator of soil compaction in a felling area $[3,4]$.

Another important aspect of research directed at environmental impacts of forest machinery on the soil in felling areas is the interaction with permafrost soils of cryolithic zone forests as particularly susceptible forest ecosystems [5,6] subjected to extensive commercial exploitation $[7,8]$.

Skidding is considered as the most environmentally harmful operation in wood harvesting [9]. The interaction of the tractor's skidding unit and the dragging part of the felled timber bunch may cause significant degradation of the soil structure [10]. There are no detailed studies on the problem of skidding systems and soil interaction, which allow estimating the influence of forest machinery maneuvers on the change of soil density in side strips of the trail when transporting a bunch of tree-length logs.

When assessing the impact of skidding methods on the soil, one of the main tasks is to establish the features of soil deformation and compaction under the action of individual elements of the skidding system - forwarder, limbs, butts, and tops [11].

However, this type of timber transportation is the most common, and new methods of more gentle impact on the soil have not yet been found. Therefore, establishing such methods are relevant 
and in high demand to date. The purpose of this work was to develop a mathematical model for estimating processes of soil deformation and compaction under the influence of certain parts of the skidding system. The model of a single log impact on the soil is based on establishing calculation formulas for determining soil compaction factors and shelterbelt size. Assessing the efficiency of the model was performed on different soil categories and compared to the results of experimental studies. Obtained results can be applied to draw up technological maps at projecting logging areas with minimization of harmful impact on the forest soil.

\section{MATERIALS AND METHODS}

During the skidding process, it is not possible to maintain the given direction of traffic precisely, and the skidding machinery may rotate. As when maneuvering off-road vehicles, it leads to additional shearing stress in a direction perpendicular to that of a normal load of the forwarder and, thus, has a destructive effect on the soil structure and adversely affects its fertility [12].

Along with evaluating the rotational force, great interest has been drawn to studying the impact of a bunch weight on the soil. In particular, the lump part of a bunch can cause an additional compaction during skidding [13].

Figure 1 depicts the pressure of concentrated force $Q=P+G$ exposed on the soil, where $Q$ is the gravity force of tree-length, $P=0.3 Q$ is the weight of tree-length acting on the tractor, $G=0.7 Q$ is the weight of tree-length acting on the soil when it is skidded at the top. At this, some part of a treelength log can go into the soil to a certain value of primary immersion area $h_{\mathrm{o}}$.

Taking into account the relation of the butt standard radius obtained by taxation value of the trunk diameter $d$, the value $h_{\mathrm{o}}$ can be determined as:

$$
h_{0}=\left(3^{n} \beta \frac{\pi h_{k} G}{A L \sqrt{d}}\right)^{\frac{1}{n+1,5}}
$$

where the coefficient $\beta \geq 1$ is the relation of $L$ to the maximum possible hanging part of the tree-length $\log$, and $A$ and $n$ are the parameters of soil and press tool of weight $G$ with contact area $d$ in exponential functions $q=A h^{n}$, i.e., in dependencies of press tool pressure $q$ on the depth of its immersion $h$ within the range from 0 to the depth $H$ of the deformation area.

Figure $1 b$ presents a calculation pattern for stress arising in the soil under the action of force $G$ within the deformation area $H$ at the contact and immersion of the butt part of a tree-length log into the soil considering its possible rotation at a certain angle $\theta$.

The tree-length part operating on the soil with the bark volume $V_{x}$ is determined by values $L$ and $d$ of the assortment tables and is calculated as an equivalent in volume and weight sphere with a radius:

$$
R=\sqrt[3]{\frac{0,7 V_{x}}{\pi}}
$$

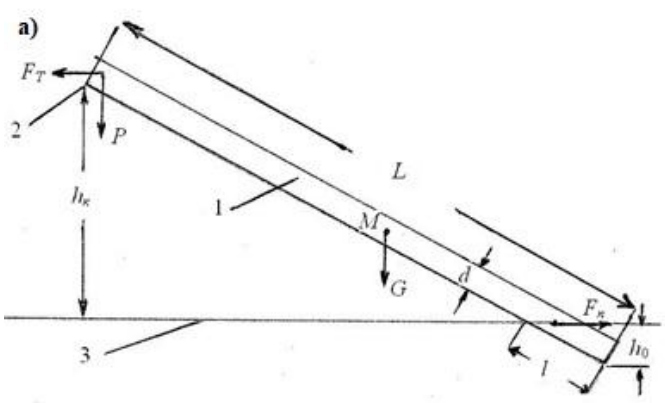

b)

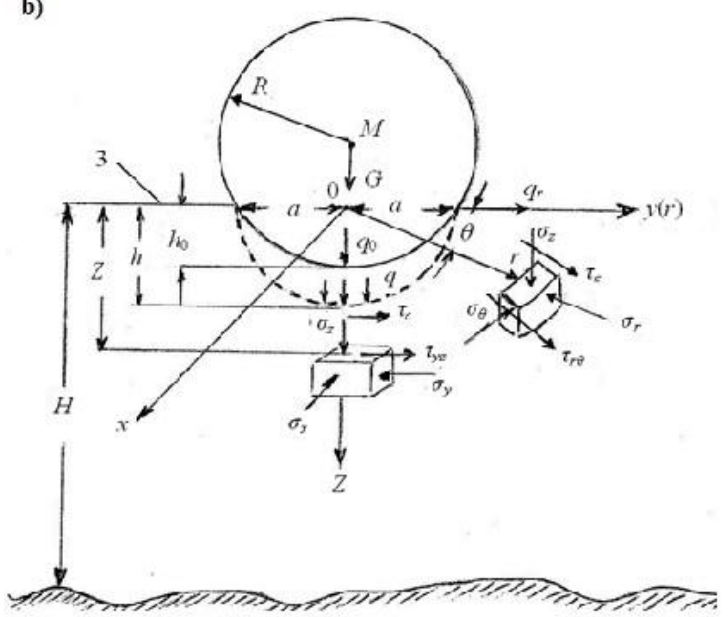

Fig. 1. The stress calculation scheme for the impact of a tree-length butt on the soil: a) scheme of a butt immersion; b) stress calculation scheme; $M$ - tree-length center of gravity, $h_{\kappa}$ the distance from point 2 of the tree-length log support on the bolster to the supporting surface

$3, L$ - the length of a tree-length log; $l$ - the length of a tree-length log in the contact area and immersion to the depth $h_{o}$

centered at point $M$. This concept allows using the mathematical model of area deformation based on the principles of contact fracture mechanics under the action of a spherical indenter with radius $R$ on the elastic half-space.

Within this model, the main characteristics of the indenter immersion into the area are the values of contact approach $h_{\mathrm{o}}$ and radius of the contact area

$$
a=\sqrt{h_{0} R},
$$

where the initial uniform pressure averaged over the area operates

$$
q_{o}=\frac{G}{\pi a^{2}}=\frac{G}{\pi h_{0} R} .
$$

Initial contact parameters at the following basic soil loading data were estimated. Single tree-length $\log$ skidding is carried at $L=30.5 \mathrm{~m}, d=0.24 \mathrm{~m}^{3}$, $V_{x}=0.65 \mathrm{~m}^{3}, h_{k}=1.8 \mathrm{~m}, l=1.525 \mathrm{~m}, \beta=1.05$. 
The skidding road lays on a moist soil with a moisture value $W$ approximately equal to the yield strength $W_{T}$. The initial density of natural soil foliage is accepted as $\rho_{\mathrm{o}}=800-900 \mathrm{~kg} / \mathrm{m}^{3}$; Young's modulus $E=1 \mathrm{Mpa}$; internal adhesion value is $C=12$ $\mathrm{kPa}$; angle of internal friction is $\varphi=15^{\circ}$; bearing capacity is $q_{s}=60 \mathrm{kPa}$; Poisson's coefficient is $v=0.25 ; H=0.4 \mathrm{~m}$. For such loading conditions, the values of coefficients $A=0.0564$ wt. and $n=1.0206$ included in the formula (1) have been determined, using the following contact parameters: $h_{o}=0,047$ $\mathrm{m} ; a=0,157 \mathrm{~m} ; R=0,53 \mathrm{~m} ; q_{o}=61,64 \mathrm{kPa}$.

The process of soil deformation outside the contact zone with depth $h_{\mathrm{o}}$ and radius $a$ will be considered in a Cartesian coordinate system. At the elementary sites, the stress (Fig. $1 b$ ) is determined as follows:

a) vertical stress: $\sigma_{z}=$

$$
-q_{0} \psi_{z}(r, z)=\left(-q_{0} \frac{z}{\sqrt{u}}\right)^{3} \frac{a^{2} u}{u^{2}+a^{2} z^{2}},
$$

b) horizontal stress: $\sigma_{y}=q_{0} \psi_{y}(r, z)$,

where

$$
\begin{aligned}
& \psi_{y}(r, z)=\frac{1-2 v}{3} \frac{a^{2}}{r^{2}+z^{2}}\left[1-\left(\frac{z}{\sqrt{u}}\right)^{3}\right]+\left(\frac{z}{\sqrt{u}}\right)^{3} \frac{a^{2} u}{u^{2}+a^{2} u^{2}}+ \\
& +\frac{z}{\sqrt{u}}\left[\frac{(1-v) u}{a^{2}+u}+(1+v) \operatorname{arctg}\left(\frac{a}{\sqrt{u}}\right)-2\right]
\end{aligned}
$$

c) tangential stress: $\tau_{y z}=$

$$
-q_{0} \psi_{y z}(r, z)=-q_{0} \frac{a \sqrt{u} z^{2}\left(r^{2}+z^{2}\right)}{\left(u+a^{2}\right)\left(u^{2}+a^{2} z^{2}\right)} \text {, }
$$

where $\psi_{z}(r, z), \psi_{y}(r, z)$, and $\psi_{y z}(r, z)$ are coordinate functions and $u$ is the positive root of quadric equation

$$
\frac{r^{2}}{a^{2}+u}+\frac{z^{2}}{u}=1
$$

The component $\sigma_{x}$ can be defined through the lateral expansion of the soil as

$$
\sigma_{x}=\frac{v}{1-v} \sigma_{z}
$$

Since the problem is considered as axisymmetric, the $y$-axis can be replaced by the $r$ axis, where $r$ is the radial distance from the center of contact to the calculation contact point, i.e., accepting that $\sigma_{y}=\sigma_{r}$.

As follows from Eq. (5), the stress state of the soil depends on the coordinates of the calculation contact point and the radius of the contact area $a$, which in turn depends on $h_{\mathrm{o}}$ and $R$.

The analysis of dependencies of variable dimensionless functions $\psi_{z}(r, z), \psi_{y}(r, z)$, and $\psi_{y z}(r, z)$ on the relative value $\bar{h}=z / h_{0}$ directly under the spherical indenter $(r=0)$ allows drawing some conclusions. First, the negative (compressing) vertical $\sigma_{z}$ and mainly positive (stretching) radial stress $\sigma_{r}$ indicate that the soil deformation occurs through the shearing. Second, the values of shear stress $\tau_{y z}$ are close to zero and slightly varies with bigger depth and increasing z-coordinate. This means that the components $\sigma_{z}, \sigma_{u}$, and $\sigma_{x}$ can be accepted as the main ones, i.e., $\sigma_{1}, \sigma_{2}$, and $\sigma_{3}$, respectively.

The combined action of the vertical force $G$ and tangential (horizontal) force $F_{T}$ of the tractor's traction required to move the skidding system initiate the force of resistance to tree-length $\log$ sliding $F_{n}$. At that, the soil deformation occurs in the direction of this force (Fig.1a). Consequently, horizontal stress $\tau_{s}$ is formed perpendicular to the action of vertical stress $\sigma_{z}$ leading to the soil deformation through the shearing (Fig. 1b).

Horizontal stress $\tau_{c}$ relates to vertical stress $\sigma_{z}$ through Coulomb's law perspective:

$$
\tau_{c}=\sigma_{z} \operatorname{tg} \varphi+C
$$

At the moment when the tractor and, then, the tree-length $\log$ deviates from the given traffic direction to the angle $\theta$, the soil deformation is expedient to consider in the cylindrical system of coordinates $z r \theta$.

Generally, the components of the stress tensor in this system at existing shear stress $\tau_{r \theta}$, which coincide in the direction with the action of horizontal stress $\tau_{c}$, are determined as:

$$
\begin{array}{cc}
\sigma_{z}=\sigma_{1} ; & \sigma_{r}=\frac{\sigma_{2}+\sigma_{3}}{2}+\frac{\sigma_{2}-\sigma_{3}}{2} \cos 2 \theta ; \\
\sigma_{\theta}=\frac{\sigma_{2}+\sigma_{3}}{2}-\frac{\sigma_{2}-\sigma_{3}}{2} \cos 2 \theta ; & \tau_{r \theta}=-\frac{\sigma_{2}-\sigma_{3}}{2} \sin 2 \theta .
\end{array}
$$

From Eqs. (8) follows that at $\theta=0$, the stress tensor components dominate, i.e., $\sigma_{z}=\sigma_{1}, \sigma_{r}=\sigma_{2}$, $\sigma_{\theta}=\sigma_{3}$, and $\tau_{r \theta}=0$.

The resultant value $\tau=\tau_{c}+\tau_{r \theta}$ characterizes the total shear stress, and the exceedance of $\tau$ value over the bearing capacity limit of the soil $q_{s}$ is assumed as destruction criterion, i.e.:

$$
\tau \geq q_{S}
$$

The value $z$, under which the condition (9) is completed, can be considered as the limit value of the contact approach or the maximum possible depth of the tree-length immersion area $h_{s}$.

Stress tensor components were determined by equation (5), and total shear stress $\tau, \mathrm{kPa}$, depending on the relative coordinate $\bar{h}$ for different values of the rotation angle $\theta$ within the range from 0 to $25^{\circ}$ was calculated based on Eqs. (7) and (8).

The calculation showed that at skidding of a single tree-length log over the given soil without any maneuvers of a skidding system, the deformation criterion by shearing (9) is not valid outside the contact area $(\bar{h}=1)$, i.e., the soil deformation through shearing does not occur outside the primary immersion area $\left(z=h_{\mathrm{o}}-0.047\right.$ $\mathrm{m})$.

By tree-lengths rotation $\left(\theta=10-25^{\circ}\right)$, the immersion area becomes larger, and its depth $h_{s}$ increases from 0.058 to $0.082 \mathrm{~m}(\bar{h}=1.25-1.75)$. The radius of the contact area $a$ expands in this case from 0.176 to $0.208 \mathrm{~m}$. Concerning the adopted law of changes $q(h)$ and obtained coefficients $A$ and $n$, 
the specified values of $h_{s}$ are related to the values $q$ of the load exercised on the soil from the spherical indenter with radius $R$ within the range $q=27.3$ $48.33 \mathrm{kPa}$ for a skidding of a single tree-length $\log$.

The processing of the graphical concept of the calculation results using correlation-regression analysis allowed the definition of the dependence of $\tau$ on $\bar{h}$ with a high determination coefficient $(\mathrm{R} 2>0.93)$ and considering the angle parameter $\theta$ for a single tree-length:

$$
\tau=\lambda \bar{h}^{\eta}
$$

where the coefficients $\lambda$ and $\eta$ are functions of the angle $\theta$ :

$$
\begin{gathered}
\lambda=0,7605 \theta+23,913 \\
\eta=-(0,0179 \theta+0,241)
\end{gathered}
$$

The Eqs. (9) and (10) show that the depth limit of the immersion area $h_{s}$ can be defined as:

$$
h_{s}=h_{0}\left(\frac{q_{s}}{\lambda}\right)^{\frac{1}{\eta}} \text {. }
$$

The value of a relative soil compaction within the trail is defined as:

$$
\bar{\rho}=\rho / \rho_{0}=\varepsilon+1=\frac{h_{s}}{H}+1,
$$

where $\rho$ is the achieved soil density and $\varepsilon$ is the deformation of compression.

The radial stress $q_{r}$ along the radius $r \geq a$ calculated from the boundary of a contact area is described by the ellipse equation:

$$
q_{r}=q_{0} \sqrt{1-(a / r)^{2}} \text {. }
$$

Thus, the value $q_{r}$ is 0 when $r=a$ at the site boundary, and it will increase with bigger relative distance $r / a$.

The maximum radial distance $r_{s}$, at which value $q_{r}$ will exceed the soil bearing capacity $q_{s}$, can be interpreted as the size of the maximum compaction area in the radial direction from the track or as the width of a shelterbelt of undergrowth root system or cut-to-length wood. It can be expressed as follows:

$$
r_{S}=a \sqrt{\frac{1}{\left(1-\frac{q_{S}^{2}}{q_{0}^{2}}\right)}} .
$$

Experimental studies of soil compaction on the side strands of a trail during skidding a bunch of tree-length $\operatorname{logs}$ were performed under laboratory conditions using a metrologically verified DOS-3-I electronic compression dynamometer including $101 \mathrm{WN}$ strain sensor and indicator station R320. The analysis results were processed by special software and data retransmission to Excel application [14-16].

For the tests was used a press tool obtained from cylindrical wooden blanks and shortened so that when pushed into the experimental soil, the contact area in the geometric ratios repeats the contact area of $\log$ butts during skidding. Three types of soils were used for the experiment:
- Category I - sand, loamy sand, light clay (wet), top soil, and peat;

- Category II - loam, gravel fine and medium, and light clay (wet);

- Category III - clay medium or heavy, loosened, and dense loam.

The soil selected from the cutting area was placed into the tray so that the distance from the soil surface to the bottom of the tray was $0.16,0.08$, and $0.06 \mathrm{~m}$ when examining the soil compaction of the first, second, and third categories, respectively. A press tool corresponding to a soil category was attached to a circular plate of $0.4 \mathrm{~m}$ in diameter and manually immersed into the soil placed in the tray. At that, the plate with the attached press tool tightly fitted to the soil surface. Afterward, the press tool and the plate were rotated to the specified angle $\theta$, wherein the measuring equipment of the sensor recorded the value of force applied to the indicator part of the strain sensor from the side of the soil under deformation.

The main independent parameters to be monitored during the research were soil density used in the tests and consistency index. As variables were applied the die rotation angle $\theta$ and the distance from the die to the adjoining soil layer, for which the compressing force was measured at rotating the die. The output parameter was the maximum compressive force $\mathrm{P}$ occurring at the side soil layer adjacent to the die at its rotation. Based on the analysis, a three-level full-factor experiment was performed.

In mathematical modelling, the reinforcing effect of the root system of trees and shrubs on the soil of the cutting area is measured using Young's module, the Poisson coefficient, and other coefficients, whose values are determined empirically. Soil sampling devices are usually employed to determine the root content of the soil. Obtained soil samples are dried, and the parts of roots are then selected and weighted to define the soil-to-root ratio. At other equal conditions, the larger the root system, the stronger the soil. This method is time-consuming and not effective.

In Grigoriev et al. [17] the original design of a hand-held device that provides an effective definition of foliage coverage of the trees and shrubs root systems is proposed (fig. 2). It consists of a handle with an indicator and a hollow rod. The working component is a platform $1.0 \times 0.5$ meters in size fixed in the center of the rod perpendicularly. At the bottom, there are springloaded needles fitted in sockets. Spring force is selected according to the soil strength category. The needles are provided with normally opened circuits, which are connected to a single electrical circuit powered by a battery. The working body of the device is connected to the indicator by a wire passing in the hollow rod. 


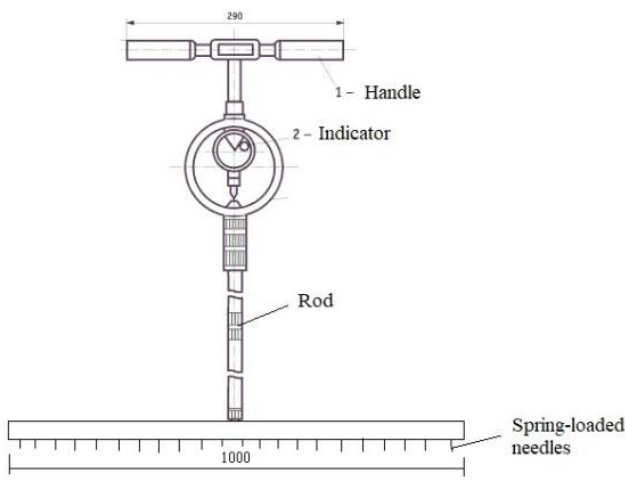

Fig. 2. Design of the device for effective determination of the root system foliage cover [17]

When pressing the platform with needles into the soil, part of the needles will not meet the roots in its path and will immerse into the soil without pressing the contact. The needles, which meet a root or other solid obstacle in their path, will overcome the force of the spring under the force applied by the examiner to the handle, immerse into the socket and close the contacts.

The indicator scale is marked with the percentage of needles that have closed their contacts. That is, if no needle met a solid obstacle (sandy beach variant), the arrow is at 0 mark. If half of the needles encounter an obstacle, the indicator shows a value of 50 , etc.

Besides a simple mechanical arrangement of the device, it is also cost-effective in manufacturing and reliable in operation. The options of its electrical measuring system have been developed and can be provided upon request.

\section{RESULTS AND DISCUSSION}

According to ratio (15), for a single tree-length skidding the range of changes $r_{s}$ is $0.25-0.30 \mathrm{~m}$ at initial parameters $q_{s}=30 \mathrm{kPa}$ and $q_{\mathrm{o}}=41.64 \mathrm{kPa}$.

Having performed similar calculations for a wider range of tree-length rotation angle variation $\left(\theta=0-45^{\circ}\right)$, the threshold values $h_{s}, a$, and $r_{s}$, were fixed, and the deformation of compression value $\varepsilon$ was then estimated.

It has been established that the maneuvers of the skidder significantly influence the value $\varepsilon$ (the range of $\varepsilon$ values varies from 0.12 to 0.23 ) and, accordingly, the value of relative compaction $\bar{\rho}$, while the size of a shelterbelt remains within quite a narrow range $r_{s}=0.23-0.33 \mathrm{~m}$.

Afterward, the associate effect of cycling and skidder's maneuvers on the relative compaction $\bar{\rho}$ was analyzed. At that, the number $(N)$ of skidder passages through the same trail was accounted by multiplying the calculated value $\varepsilon$ by the coefficient $\lambda_{N}=1+\lg N$. The results of the analysis show a significant variability of value $\bar{\rho}$ even in case of a single tree-length skidding.
The developed model of the impact of single tree-length on the soil was the basis for calculating the skidding of a similar bunch of tree-length in the amount of $N_{x}=2,3-10$ units of volume up to $V_{x}=$ $6.5 \mathrm{~m}^{3}$ and weight up to $Q=32.5 \mathrm{kN}(G=22.75$ $\mathrm{kN}$ ). The initial contact parameters at $N_{x}=10$ were obtained: $h_{o}=0,117 \mathrm{~m} ; a=0,363 \mathrm{~m} ; R=1,13 \mathrm{~m}$; $q_{o}=78,3 \mathrm{kPa}$.

Based on stress tensor components estimation (5), the calculations were performed so that the deformation criteria (9) is true. Afterward, the soil compaction parameters $\bar{\rho}$ and the size of the shelterbelt $r_{s}$ were established.

According to the performed calculation, the absolute values of $r_{s}$ increased substantially and varied within 1.1-1.6 m. The deformation of the soil compaction $\varepsilon$ has also increased and reached a value of 0.8 .

A comparison of the calculation data with the experimental values of the density change $\rho$ of the soil under the wheels of forwarder from natural composition to the tenth double passage of the skidder over the trail while skidding a bunch of tree-length $\operatorname{logs}$ led to the conclusion that the processes of soil compaction under a load of the forwarder and the bunch of logs are comparable and have similar values of relative compaction $\bar{\rho}$.

Limiting the value $\bar{\rho}$ to 2 , which means that the soil is compacted to the full depth $H$ of the deformation area, implies that the increase in value $N$ necessitates a substantial reduction of machinery maneuvers or a corresponding reduction in the weight of a skidded bunch.

The calculation results of the compaction parameters for different soil categories are presented considering its possible variations within the given boundaries of a skidding trail. Calculations are made for three soil categories. Depending on the ratio of moisture values $W$ versus its yield strength $W_{T}$, three categories can be defined: I - mild $\left(W>W_{T}\right)$, II - medium $\left(W=W_{T}\right)$, and III - solid soil $\left(W<W_{T}\right)$.

For all soil categories, the density of natural composition $\rho_{\mathrm{o}}$, Young's modulus $E$, the internal coupling value $C$, the internal friction angle $\varphi$, bearing capacity $q_{s}$, Poisson coefficient $v$, and loading parameters $A, n$, and $N$ were determined. The calculations of the values of $h_{0}, a$, and $q_{o}$ are given in Table 1.

The value of relative soil compaction within the trail boundary and the size $r_{s}$ of the maximum compaction area in the radial direction from the track, i.e., the width of the shelterbelt of undergrowth or cut-to-length root system (Eq. (15)), were estimated based on the initial contact parameters and using data from Eqs. (13) and (14).

The analysis of Eqs. (11), (13), and (15) displays that the values $\bar{\rho}$ and $r_{s}$ at constant skidding parameters are determined by initial parameters of contact deformation, by the value of 
the soil bearing capacity $q_{s}$, and by skidder rotation angle $\theta$.

Table 1. Assessment of initial parameters of contact deformation for different soil categories

\begin{tabular}{|c|c|c|c|}
\hline \multirow{2}{*}{$\begin{array}{r}\text { Parameter } \\
\mathrm{s}\end{array}$} & \multicolumn{3}{|c|}{ Soil categories } \\
\hline & I & II & III \\
\hline$E, M p a$ & 0.4 & 1 & 3 \\
\hline$v$ & 0.35 & 0.25 & 0.15 \\
\hline$C, k P a$ & 5 & 12 & 24 \\
\hline$\varphi,^{o}$ & 11 & 15 & 16 \\
\hline$\rho_{o}, \mathrm{~kg} / \mathrm{m}^{3}$ & 750 & 850 & 950 \\
\hline$q_{s}, k P a$ & 40 & 60 & 80 \\
\hline $\begin{array}{r}A, w t . \\
\text { (mass unit) }\end{array}$ & 0.0215 & 0.0564 & 0.1671 \\
\hline$n$ & 1 & 1.0206 & 1.0888 \\
\hline$H, m$ & 0.8 & 0.4 & 0.3 \\
\hline$h_{o}, m$ & 0.173 & 0.117 & 0.074 \\
\hline$a, m$ & 0.443 & 0.363 & 0.289 \\
\hline$q_{o}, k P a$ & 52.67 & 78.34 & 123.53 \\
\hline
\end{tabular}

By defining the $\bar{\rho}$ and $r_{s}$ values, in a straightline passage of a skidder $\left(\theta=0^{\circ}\right)$ for category I soils, the values of $\bar{\rho}$ and $r$ were 1.67 and $1.69 \mathrm{~m}$, respectively, for the category II soils $\bar{\rho}=1.4$ and $r_{s}$ $=0.93 \mathrm{~m}$, and for category III soils $\bar{\rho}=1.28$ and $r_{s}$ $=0.65 \mathrm{~m}$. Thus, if the value $\bar{\rho}$ varies from 1.28 (solid soils) to 1.67 (mild soils), i.e., by $30.5 \%$, the respective values of $r_{s}$ differ by more than 2.5 times. This indicates the need to consider detailed characteristics of the soil in designing the skidding routes in order to determine the size of undergrowth shelterbelts.

Mathematical modelling allowed identifying the dependencies of $\bar{\rho}$ and $r_{s}$ final values on the skidding parameters for all soil categories. These are the number of tree-length units $N_{x}$, its diameter and length, the height of the bunch placement on the bolster $h_{\kappa}$, skidder rotation angle $\theta$, and the repeatability parameter $N$.

Table 2 presents the calculation results of values $\bar{\rho}$ (in numerator) and $r_{s}$ (in denominator) when $N_{x}$ changes from 1 to 10 , but other parameters remain constant.

Table 2. Compaction estimates for different soil categories with variable number of units in a bunch

\begin{tabular}{|r|r|r|r|}
\hline$N_{x}$ & \multicolumn{3}{|r|}{ Soil category } \\
\cline { 2 - 4 } value & $\mathrm{I}$ & $\mathrm{II}$ & $\mathrm{I}$ \\
\hline 1 & $1.26 / 0.95$ & 1 & $1.26 / 0.95$ \\
\hline 3 & $1.41 / 1.18$ & 3 & $1.41 / 1.18$ \\
\hline 5 & $1.51 / 1.37$ & 5 & $1.51 / 1.37$ \\
\hline 7 & $1.58 / 1.50$ & 7 & $1.58 / 1.50$ \\
\hline 10 & $1.67 / 1.69$ & 10 & $1.67 / 1.69$ \\
\hline
\end{tabular}

Dependencies $r_{s}\left(N_{x}\right)$ are considered to behave logarithmically, which shows that the $N_{x}$ value has the greatest influence at 4-6 tree-length units in a bunch.
Taking the data of Table 2 as a baseline, the values $\bar{\rho}$ and $r_{s}$ were determined according to the variation of other skidding parameters $h_{\kappa}, \theta$, and $N$. Obtained dependencies also behave logarithmically. The analysis showed that when $h_{\kappa}$ is changed by $100 \%$, the change of $\bar{\rho}$ does not exceed $8 \%$, i.e., the influence of $h_{\kappa}$ on the soil compaction process can be considered as not essential. A similar conclusion is made when estimating the effect of $h_{\kappa}$ on value $r_{s}$.

Results of performed analysis revealed the significant influence of the skidder rotation angle $\theta$ on the compaction value $\bar{\rho}$ and value $r_{s}$ for all soil categories. Hereat, curves of the charts $\bar{\rho}(\theta)$ and $r_{s}(\theta)$ achieve the asymptotic level after reaching certain values of angle $\theta$.

Despite the significantly higher values of $\bar{\rho}$ and $r_{s}$ for the mild soils compared to the stronger ones, the impact of the angle parameter in mild soils is much smaller.

The repeatability of the soil compaction process considering the possible turning maneuvers of the skidder indicates that this parameter is significant in determining the accepted values of soil compaction by the skidded bunch of tree-lengths.

Since it is impossible to keep the angle $\theta$ and the soil bearing capacity $q_{s}$ constant, a statistical approach was applied to define $\bar{\rho}$ and $r_{s}$ values with possible variations of $\theta$ and $q_{s}$ values.

The adopted concept implies the generation of 100 random $\xi_{i}$ numbers distributed according to the normal law with zero mathematical expectation and single dispersion. Next, at the given technological parameters of skidding, different mathematical expectations $(M)$ of parameters $\theta$ and $q_{s}$ were defined in the range from 0 to $60^{\circ}$ for $M(\theta)$ and from 40 to $80 \mathrm{kPa}$ for $M\left(q_{s}\right)$. The coefficients of variation $\left(K_{v}\right)$ were $0-0.5$ (50\% variation) for $K_{v}(\theta)$ and $K_{v}\left(q_{s}\right)$, respectively.

Afterward, 100 values of $\theta$ and $q_{s}$ are determined as follows:

$$
\theta_{i}=M(\theta)\left\{1+k_{v}(\theta)\right\}, \quad q_{s i}=M\left(q_{s}\right)\left\{1+K_{v}\left(q_{s}\right)\right\},
$$

which are substituted in Eqs. (11), (13), and (15) resulting in 100 values of $\bar{\rho}$ and $r_{s}$.

Statistical processing of the samples of obtained values $\bar{\rho}$ and $r_{s}$ allows establishing variation coefficients $K_{v}(\bar{\rho})$ and $K_{v}\left(r_{s}\right)$. With the possible deviations of $\theta$ and $q_{s}$, it is possible to establish allowable limits of $\bar{\rho}$ and $r_{s}$ variation for each soil category studied.

For example, for the second soil category at $\mathrm{M}(\theta)=10^{\circ}$ the variations of $\theta$ and $q_{s}$ values within $20 \%$ provide $K_{v}(\bar{\rho})=5 \%$ and $K_{v}\left(r_{s}\right)=8 \%$, which at $M(\bar{\rho})=1.5 \mathrm{~m}$ and $M\left(r_{s}\right)=1.08 \mathrm{~m}$ sets a tolerable variation of $\bar{\rho}$ from 1.42 to $1.58 \mathrm{~m}$, while 
$r_{s}$ remains within $1-1.17 \mathrm{~m}$. Noteworthy is that the $20 \%$ variation means stable conditions of skidding. A more significant variation of parameters occurs at $K_{v}>30 \%$.

Another conclusion relates to the influence of the soil category. In milder soils, the variability of $\theta$ and $q_{s}$ parameters determines wider limits of allowable variation ranges of $\bar{\rho}$ and $r_{s}$ values. Thus, the comprised mathematical model and the results of the research allow calculating of parameters and indicators of the skidding system and allowable variation range for indicators stabilization [14].

Laboratory experiments had confirmed the validity of the comprised mathematical model. After comparing the calculated data with the experimental dependencies for the case of tree-length skidding, it was concluded that by predicting the size of a shelterbelt at tree-length skidding, the calculation data differ from experimental by no more than $10 \%$.

The distance between the skidding trails must be at least $20 \mathrm{~m}$, preferably longer in more vulnerable woodlands. In general, the reach of a boom in modern harvesting machines is up to 10 meters. Thus, their operating range, i.e., the areas between the skidding trails on which the machines can effectively use the boom, is almost $20 \mathrm{~m}$. Similar conclusions are drawn by other researchers $[11,18]$.

The 4-meter-wide skidding roads at a distance of 20 meters imply that at least $20 \%$ of the forest stand covered by forest machinery. This percentage may be reduced by laying access roads at a greater distance from each other. Trees outside the reach of a skidder can be cut down manually in the direction of the machine so that the trunk would be within the reach of harvesting arm. Moreover, machines should move without turning within one straight line as much as possible to prevent the soil wounding on the roadsides.

It is important to consider the balance between access roads and wood production areas. Narrower distance between the tracks may lead to a reduction in the volume and value of production due to the soil compaction in the wood stands. However, wider spacing would increase the cleaning costs. Frutig et al. [18] found that a wider interval (optimum: 30-50 $\mathrm{m})$ is advisable in the long-term perspective, as losses due to slower growth and less valuable wood are of great importance in calculating the entire turnover period. This conclusion coincides with the results obtained in this study.

Wood shrub cover made of cut-down and delimbed trees can have a protective effect on skids and reduce the impact of heavy machinery on the forest soil. Kremers and Boosten [11] concluded that no major changes in soil structure occurred on the skidding roads covered with brushwood.

With the shrub wood covers, the weight of the machine is distributed over a larger contact area than the landing area of machinery, thereby reducing the contact pressure on the soil. However, this method requires the tree-length $\operatorname{logs}$ to be carried, not skidded, out of the forest so that the brushwood cover remains intact [19].

However, the question of whether these wood covers provide sufficient protection in all situations is disputable. Another argument to consider is the displacement of nutrients in forest plantations, since, all organic matters usually spread throughout the plantation are now concentrated on the skidding trails.

\section{CONCLUSIONS}

According to the results of the study, it can be concluded that the developed mathematical model for estimating the processes of soil deformation and compaction under the influence of the skidded part of the timber bunch is quite accurate and effective. Predicting the size of the shelterbelt at skidding a bunch of tree-length logs considering the results of the experiments, the calculation data differ from experimental by not more than $10 \%$. Besides, the results of modelling showed that the deformation of the soil by the bunch of tree-length logs occurs due to shearing processes, wherein the initial vertical (compressing) stress exceeds the radial (stretching) stress by $30-40 \%$. Performed analysis allowed determining correlation between the intensity of total shear stress reduction and the size of the soil compaction area. Estimating the dependency of the shelterbelt width on the number of tree-length logs in a bunch for three different soil categories (mild, medium, and solid) showed, that a limit values for logs amount to 4 till 6 units depending on the soil category, accordingly.

Developed model can be applied to draw up a technological map for projecting a logging area based on soil and skidding system specifics. The proposed technical solution for the effective determination of the foliage cover of trees and shrubs root systems is aimed at increasing the efficiency of forest research while preparing it for harvesting operations. Also, by expanding the range of research parameters, it allows increasing the efficiency of cutting areas examination.

\section{ACKNOWLEDGMENT}

The work was carried out within the confines of the scientific school "Advances in lumber industry and forestry"

\section{REFERENCES}

1. Knox JH. Report of the Special rapporteur on the issue of human rights obligations relating to the enjoyment of a safe, clean, healthy and sustainable environment: Biodiversity Report. United Nations Human Rights Council, A/HRC/34/49; 2017.

2. Marchi E, Chung W, Visser R, Abbas D, Nordfjell T, Mederski PS, Laschi A. Sustainable Forest Operations (SFO): A new paradigm in a changing 
world and climate. Science of the Total Environment 2018;634:1385-1397.

https://doi.org/10.1016/j.scitotenv.2018.04.084

3. Kuosmanen, T., Kortelainen, M. Measuring ecoefficiency of production with data envelopment analysis. Journal of Industrial Ecology, 2005; 9(4): 59-72. https://doi.org/10.1162/108819805775247846

4. Rudov SE, Grigorev IV, Kunitskaya OA, Druzyanova VP, Pekhutov AS, Ivanov AP, Ivanov AK, Okhlopkova MK, Pankov VYu, Borovikov RG. Specific accounting features of permafrost soil condition under cyclic loads. Bulgarian Journal of Agricultural Science 2019; 25: 191-205.

5. Iijima Y, Fedorov AN. Permafrost-Forest Dynamics. In: Water-Carbon Dynamics in Eastern Siberia (pp. 175-205). Springer, Singapore; 2019.

6. Zhang-Turpeinen $\mathrm{H}$, Kivimäenpää $\mathrm{M}$, Aaltonen $\mathrm{H}$, Berninger F, Köster E, Köster K, Pumpanen J. Wildfire effects on BVOC emissions from boreal forest floor on permafrost soil in Siberia. Science of The Total Environment 2020; 711: 134851. https://doi.org/10.1016/j.scitotenv.2019.134851

7. Rudov SE, Shapiro VY, Grigoriev IV, Kunitskaya OA, Grigorieva OI. Pecularities of the contact interaction of the skidding system with permafrost soil. Forest Magazine 2019; 1: 106-119.

8. Rudov SE, Shapiro VY, Grigoriev IV, Kunitskaya OA, Grigorieva OI. Variation method for calculating the interaction of the skidding system with permafrost and defrosting soils. Systems. Methods. Technologies 2019; 1: 68-77.

9. Townsend L, Dodson E, Anderson N, Worley-Hood G, Goodburn J. Harvesting forest biomass in the US southern Rocky Mountains: cost and production rates of five ground-based forest operations. International Journal of Forest Engineering 2019; 30: 163-172. https://doi.org/10.1080/14942119.2018.1563851

10. Bulat PV, Chernyshev MV. Existence regions of shock wave triple configurations. International Journal of Environmental and Science Education, 2016; 11(11): 4844-4854.

11. Kremers J, Boosten M. Soil compaction and deformation in forest exploitation. American Journal for Alternative Agriculture 2018; 7: 25-31.

12. Rudov SE, Voronova AM, Chemshikova JM, Teterevleva EV, Kruchinin IN, Dondokov YuZh, Khaldeeva MN, Burtseva IA, Danilov VV, Grigorev IV. Theoretical approaches to logging trail network planning: increasing efficiency of forest machines and reducing their negative impact on soil and terrain. Asian Journal of Water, Environment and Pollution 2019; 16: 61-75. https://doi.org/10.3233/AJW190049

13. Grigoriev IV, Zhukova AI, Ivanov AV, Rudov ME, Swoikin FV. Mathematical modelling of skidded timber bunch maneuvers on the soil of logging sites. Systems. Methods. Technologies 2011; 4: 92-96.

14. Uskov V, Bulat P, Arkhipova L. Classification of gasdynamic discontinuities and their interference problems. Research Journal of Applied Sciences, Engineering and Technology. 2014;8(22): 2248-2254

15. Grigoriev IV, Zhukova AI, Ivanov AV, Rudov ME, Swoikin FV. Results of experimental studies on the impact of wood on soil in various skidding methods. Systems. Methods. Technologies 2011; 4: 67-70.

16. Grigorev MF, Grigoreva AI, Grigorev IV, Kunitskaya OA, Stepanova DI, Savvinova MS, Sidorov MN, Tomashevskaya EP, Burtseva IA, Zakharova OI.
Experimental findings in forest soil mechanics. EurAsian Journal of BioSciences. 2018; 12 277-287.

17. Dmitrieva MN, Grigoriev IV, Rudov SE. Analysis of the interaction between grapper skidders and soils with low bearing capacity. Resources and Technology 2019; 1: 10-39.

18. Dvoynikov MV, Nutskova MV, Blinov PA. Developments Made in the Field of Drilling Fluids by Saint Petersburg Mining University. International Journal of Engineering 2020; 33: 702-711. https://doi.org/10.5829/ije.2020.33.04a.22

19. Jourgholami M. Effects of soil compaction on growth variables in Cappadocian maple (Acer cappadocicum) seedlings. Journal of forestry research 2018;29(3): 601-610. https://doi.org/10.1007/s11676$\underline{017-0491-7}$

Received 2020-04-05

Accepted 2020-07-13

Available online 2020-07-16

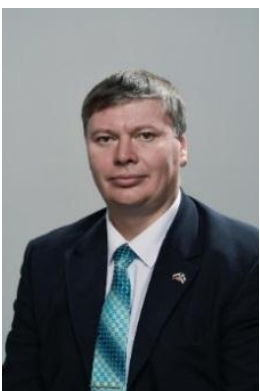

Igor GRIGOREV is a Doctor of Technical Sciences, Professor of the Department of Technology and Equipment of Forest Complex, University Yakut State Agricultural Academy, Yakutsk, Russian Federation. Field of research: logging and reforestation machinery, equipment and procedures.

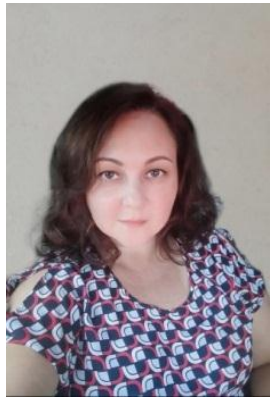

Ol'ga KUNICKAYA is a Doctor of Technical Sciences, Professor of the Department of Technology and Qquipment of Forest Complex, University Yakut State Agricultural Academy, Yakutsk, Russian Federation. Field of research: timber production; wood modification; the use of wood as energy; environmental safety of timber harvesting and processing facilities; wood chemical industry; and utilization of nontimber forest products.

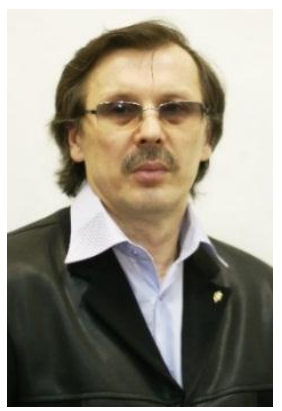

Albert BURGONUTDINOV is a Doctor of Technical Sciences, Professor of the Department of Roads and Bridges Building, Perm National Research Polytechnic University, Perm, Russian Federation. Field of research: thermal conductivity of building materials in road structures (i.e., monitoring of soil and pavement temperature at $3-\mathrm{m}$ depth); developing guidelines for traffic circle construction.

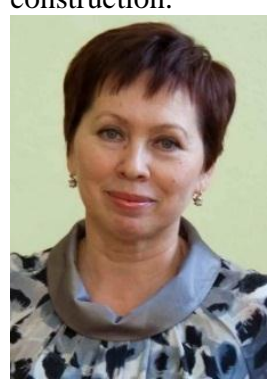

Olga BURMISTROVA is a Doctor of Technical Sciences, Professor of the Department of Technology and Harvesting Machines, Ukhta State Technical University, Ukhta, Russian Federation. Field of research: technology of harvesting and 
processing timber; forest road design, construction, and maintenance.

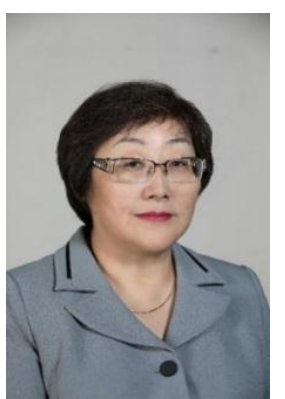

Varvara DRUZYANOVA is a Doctor of Technical Sciences, Head of Department of Operation of Road Transport and Auto Repair, Northeastern Federal University named after M. K. Ammosov, Yakutsk, Russian Federation. Field of research: cold-weather vehicle operation.

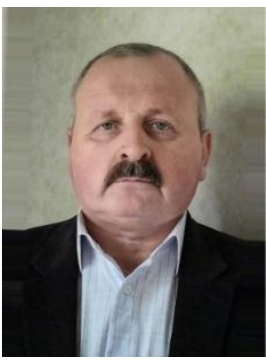

Nikolay DOLMATOV is a Candidate of Technical Sciences, Assistant Professor of the Department of Machines Environmental Engineering, Don State Agrarian University, Novocherkassk, Russian Federation. Field of research: solutions to problems with a drainage and reuse system in the irrigation zone; primarily, designs of various working bodies for pipeline maintenance machines.

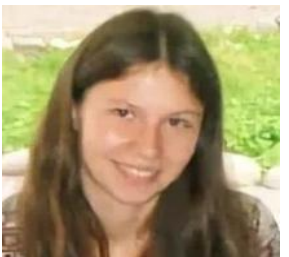

Anna VORONOVA is a Doctor of Technical Sciences, Professor of the Department of Technical Operation and Service of Transport and Technological Machines, Federal State Budget Educational Institution of Higher Education "Petrozavodsk State University", Petrozavodsk, Russian Federation. Field of research: mathematical modeling, information systems.

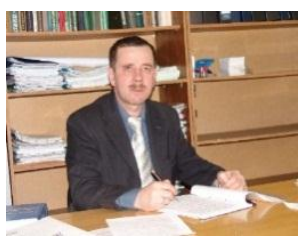

Alexey KOTOV is a Doctor of Technical Sciences, Professor of the Department of Forest Culture, Selection and Dendrology, University Moscow State Technical University N. E. Bauman (Mytishchi branch), Mytishchi, Russian Federation. Field of research: science-based fundamentals of building forest management machines; physico-mechanical properties of undesirable tree and shrubbery vegetation growing at the harvesting sites and weeds found in tree nurseries. 